\title{
Functional Well-being
}

National Cancer Institute

\section{Source}

National Cancer Institute. Functional Well-being. NCI Thesaurus. Code C91780.

The status of one's ability to perform activities of daily living and participate socially and occupationally. 